\title{
IJTARP
}

\section{The TAMED Game, Bystanders and Professional Associations}

\author{
(c) 2021 Julie Hay
}

\begin{abstract}
The author introduces a psychological game named TAMED - the TA Myth of Explanatory Depth, which she suggests provides an explanation of unhealthy dynamics occurring within transactional analysis membership and professional associations. She illustrates this with four case examples based on personal experiences. She also provides an overview of TA theory about psychological games, the bystander role, the various roles within the drama triangle and extensions of it, and the potency pyramid. She provides a selection of materials by TA and nonTA authors to support the premise that such games are more to do with organisational and group processes than the script of the individual who is seen as the cause of the conflict. The article concludes with some initial thoughts about how TA organisational diagrams need amending to reflect the structure and dynamics of professional associations.
\end{abstract}

\section{Key words}

TAMED, psychological games, role lock, potency pyramid, drama triangle, bystander, organisational cone, professional associations

\section{Introduction}

I have chosen to set the scene by including an email below as Illustration 1, in the hope that it will help the reader understand why the rest of the article has been written.

In this article I will use case examples to show how the application uncritically of Berne's original material leads to a game called TAMED - the TA Myth of Explanatory Depth. I believe there is a serious risk to the reputation of TA when we discount that Eric Berne was sexist and homophobic. The excuse that this was typical of the time is not enough of a justification. He produced some amazingly useful material and I cannot believe that he would have maintained the same views had he lived beyond 1970.
A common example is the way in which TA practitioners continue to refer to games in more or less the same way that Berne did, including referring to Rapo, NIGYSOB and Wooden Leg (Berne, 1961), which are clearly misleading and/or offensive names. I renamed these many years ago - respectively as Rebuff, Gotcha (Hay, 1993) and Millstone (Hay, 1995). It is not difficult to capture the same dynamics with a different label.

Name changes such as these are at about the same level as us changing from Chairman to Chairperson; the problem is in the psychological level of the implication. I think there are more serious dynamics occurring around the ways in which TA practitioners level the accusation of game playing when we disagree with someone else's perspective and seem determined to avoid any logical problem-solving interaction. Events over the last few years within the TA community have prompted me to consider the ways in which such accusations are made, without any apparent recognition that if someone else is playing a game with them, they must also be playing the game - or they must at least be bystanders within the negative meaning of that term. It seemed to me that that these events could be explained by what Rozenblit \& Keil (2002) called the illusion of explanatory depth. Hence my decision to call this game TAMED - the TA Myth of Explanatory Depth.

As I write this, I am conscious that I may be engaging in SPOT - Spontaneous Preference for Own Theories - described by Gregg, Mahadevan and Sedikides (2017) and referred to by them as how their research subjects "regarded the theory as more likely to be true when it was arbitrarily ascribed to them" (p. 996), rather than ascribed to another person or to no-one. I invite you to consider whether you might be doing the same, and how I and those involved in the 'stories' I tell below might also have been engaging in SPOT. Perhaps this is the process through which TAMED operates. 


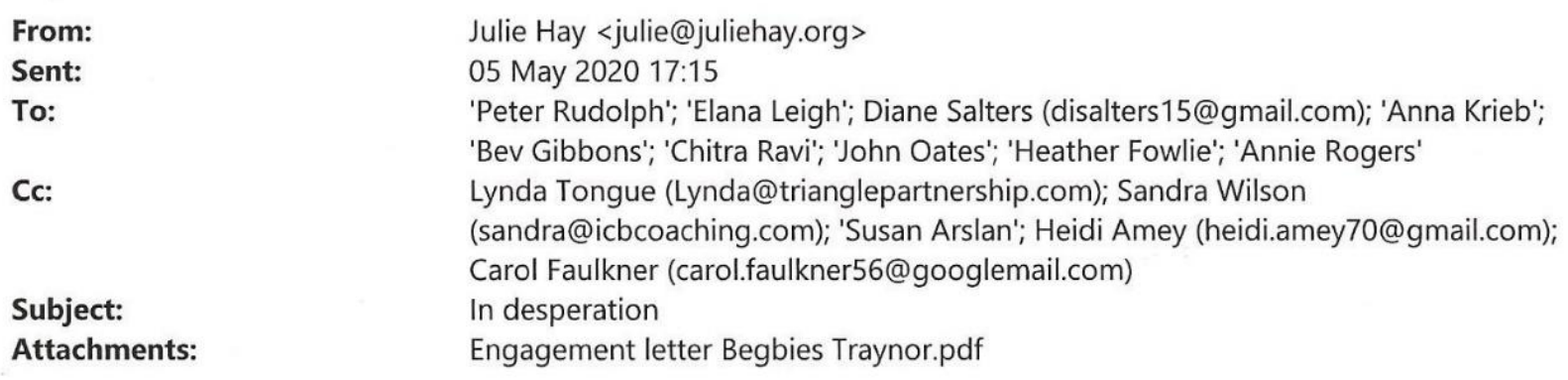

Today I am sending the proposed announcement below only to those who signed the Announcement cancelling the conference, and copying it only to the WTAC2020 Organising Committee.

I realise that some of you may not be familiar with UK law so can only assume that there has been some huge misunderstanding or incorrect legal advice given to you.

Depending on the responses I receive within the next 24 hours, I will be making the information more widely available.

I cannot delay signing the insolvency document beyond Friday morning UK time unless I get some indication that the conference can be postponed.

I am not willing to allow a situation to continue in which it appears as if I and the Organising Committee have somehow been at fault.

Julie

\section{In desperation}

One final try before I sign the attached paperwork and we waste most of the UKP 110000 still in the bank on insolvency lawyers' fees and over $\mathbf{5 5 0}$ people are left with little or no refunds and a really bad feeling about TA associations.

The associations authorised us to set up the limited company so that UKATA would not face the total financial risk. As director, I have no choice but to behave in line with UK law. When I advised people that refunds would be available, and when I gave refunds before coronavirus emerged, I had no idea that the associations would use a legal loophole to avoid their responsibilities - and no idea that coronavirus would happen - I had personally arranged conference cancellation insurance, having spent 24-hours in Mumbai airport before returning home when the conference in India was flooded.

The first negotiation that the Organising Committee were authorised to conduct had removed the risk of insolvency, which returned when the Associations refused to stand by what they had previously confirmed in writing. We negotiated again, got agreement from Hilton to postpone, and we already have nearly 300 people who have confirmed their payments can be transferred for attendance in 2023. They will all have to pay again if the insolvency proceeds.

Thanks to those who have agreed to postpone, we have enough money in the bank to pay full refunds to everyone else who needs them.

We can only give those refunds on the basis that around 300 people have accepted a guaranteed place in 2023. ITAA/EATA/FTAA/UKATA/IARTA have announced that they will favour the UK for the conference in 2023 but have refused to postpone the existing conference. They have given no explanation for this decision, which means we must now include those 300 people within the calculations for refunds, which means that the limited company is again insolvent.

It is now the puzzling decision by ITAA/EATA/FTAA/UKATA/IARTA to cancel rather than postpone the conference that will lead to everyone who has paid receiving very small or no refunds of their payments.

This applies whether the Hilton Metropole is open in July 2020 or not.

For anyone who has already applied for a refund when they saw the cancellation announcement, I had no choice but to close down the bank account because I am required under UK law to ensure that all creditors are treated equally which means that after the liquidation fees have been paid, they will all get only the same small or zero percentage of what they paid, which will then be halved if the Metropole are open in July 2020.

Illustration 1: Email to Association Presidents 
I am also recognising that I may be Rescuing (Karpman 1968) because I am aware that recognising TAMED is even more important when the individual accused of playing the game is leading projects within the TA community. This is because the public accusations exert psychological pressure on the volunteers involved in those projects to 'choose sides' and to risk being accused themselves. This is of course a strong incentive not to challenge any TA leadership figures, especially because of the unconscious power hierarchy within the TA community based on people's TA qualifications. I recall that many years ago a friend and colleague apologised for being unwilling to nominate me in the election for ITAA President because one of those I would be running against might one day be on their exam board.

I am also recalling that during my childhood my father frequently told me that I was the cause of the negative dynamic between him and my mother (screaming rows although not about me). When I learned TA, I realised that it was not true that any child is to blame for what adults do. However, as my mother become older and reminisced, I learned how I 'had' been the cause. He had told my mother that he did not want children, probably claiming it was because he was a soldier in a war. I doubt he realised that his own childhood had left him needing to get the attachment he had been denied. My mother wanted a baby so she ignored him. She went ahead and got pregnant (I do realise he contributed to that process!).

He was away for most of the next three years, so returned at the end of World War 2 to find that my mother now refused to accompany him when he played drums in a small band. I'm pretty sure she had hated sitting there alone before and used the excuse that she now had a child and good parents did not use babysitters. In addition to telling me it was my fault, he added physical to the psychological abuse. He did this in ways that did not show. When I reacted, he claimed innocence and my mother did not believe me. As you read on, you will see that my childhood strategy for dealing with being blamed is somehow evident to others who unconsciously need to bully someone about their own problematic group dynamics. It is as if I invite others not to believe me unless they are close enough to be like my brother and (very young) uncle, who knew what was happening, had their own issues, and were in any case powerless to intervene. I doubt I am the only volunteer to find their childhood history repeated, although I may be unusual in that I am less concerned with the 'seduction of normativity', which Minikin (2021) describes as underlying systemic power because "we are relationally bound with context and the wider systems in which we live." (p.36). I prefer her comments about rebellion offering critical thinking and challenging the dynamics of discounting.
Increasingly, as I have been completing this article, I have begun to notice other indications of 'unfortunate' dynamics within the TA community. McKinnon Fathi (2017) defined gaslighting as "a psychological process of manipulation designed to undermine the victim's perception of reality. It's goal is to exert control; it is an attack on the soul. Creating doubt by blurring the truth, it happens in interpersonal relationships but also in social contexts." (p.29). During 2021, several authors have written within the TA literature about bullying and I will refer to this later in terms of whether TAMED, and bullying, are really psychological games.

Cornell (2020) has written that "For societies to succeed, to mature, to be truly safe, we must have leadership that is capable of self-examination and that models the capacity to look at ourselves for solutions rather than to others. We need leadership that leads through introspection and acceptance of responsibility rather than projection and assignment of blame." (p.6). This was followed two months later by Minikin and Rowland (2020) inviting contributions to a future theme issue of the Transactional Analysis Journal based on Systemic Oppression: What Part Do We Play? Their comments include that "Inevitably, those in charge activate individual scripting and co-create scripts that promote their survival. We have seen many examples of how oppression can be the outcome of how those with power seek to retain through structures, processes, and psychological influence." (p. 9). A later invitation by the same authors (Minikin and Rowland 2021) includes prompts about "our institutional challenges, capacities and approaches to leadership... how we may consciously and unconsciously feel systemic oppression by oppressing each other in our interpersonal dealings... [and]... in what ways have we colluded with our structural and psychological processes?" (p.49). (The closing date for submissions is not until August 2021 so I await with interest what will be published.)

In terms of the context, I have also noticed that the transactional analysis associations are not alone. The British Psychological Society (BPS) have recently announced that their President Elect has been expelled after two independent external investigations upheld allegations of persistent bullying. The interim Chair of the Board of Trustees comments on this being "turbulent times, as the organisation goes through a process of significant and much needed transformation while also experiencing vigorous debate on complex and contentious issues." (McGuinness, 2021, p.4), before going on to refer to the need for stronger governance processes and being more transparent. Comments from BPS members in response to the announcement include challenges about the public shaming and career destroying communications, position the expelled individual as a 
whistle-blower, and mention major issues of governance and mismanagement.

Also outside the TA community, INSEAD Distinguished Clinical Professor of Leadership Development and Organisational Change Kets de Vries (2021) has urged us to curb our addiction to charismatic leaders who are empowered by impressionable followers. He asks if we know the name of any recent president of Switzerland, explaining that they rotate on a yearly basis. It is interesting to consider that EATA is legally based in Switzerland but the EATA Council are proposing a change to the statutes so that the EATA President can in future served two terms of office of three years each - so someone can function as president of a whole country for a year, but to lead an association of about 8000 members needs six years.

\section{Case Examples}

I am using personal experiences of four incidents in the form of case studies. I will describe them before going on to provide an overview of the TA theories of psychological games, the bystander role, and the drama triangle and potency pyramid. I am well aware that these incidents have happened because I have chosen to follow TA Professional Practices and confront colleagues when I thought it was necessary to maintain professional standards in our behaviour with each other. This is not meant in any way to be seen as challenging any colleagues about their professionalism with clients. This article includes discussion of actions by individuals within their roles; names are only included as references when some of those individuals are the authors of material cited.

\section{ITAA Ethics Case}

I first began to have serious concerns about these dynamics within the TA community when I was asked, in January 2016, by an ITAA Ethics Committee CoChair to serve as a consultant to an individual engaged in making complaints about a number of individuals, associated with a CTA exam process. I have the permission of the complainant to share the information that follows, although I am ignoring a threat made at the end of the process by the Co-Chair of dire consequences if I communicated with anyone else about the matter.

By the time the complaints process ended four years after it began, the complainant had given up because only four out of 12 complaints had been considered, with one upheld and three dismissed, and the complainant told that he was not allowed to have any more information than those results. During the time I served as consultant, I discovered that the original complaints, which were about events leading up to and following a declaration of a no-exam, had been successively rejected as a complaint about exam processes because there was no recording of an exam, even though the complaint was not about what happened during an exam; had then been rejected as a Professional Practices matter; had eventually reached ITAA President; the complainant had then been told to submit it as an Ethics complaint; and had finally been told that he must submit a separate (lengthy) form for each individual named even though the complaint was about the result of the sequence of events.

I also noted that several of the people complained about were members of ITAA Board of Trustees and/or the ITAA Ethics Committee. It seemed to me that this should have triggered something about an independent process. I was subsequently accused of being a whistle-blower (as if this was negative), in spite of having only communicated with people who had prior involvement because of the ITAA roles that they held. These accusations were made after I had pointed out at various times that:

- I was being expected to act as a negotiator on behalf of ITAA instead of supporting the complainant;

- I questioned why my TA colleagues were now facing ethics charges when the original complaint had been about procedural matters and the complainant had been forced to present them as ethical issues;

- I objected to ITAA 'bullying' the complainant by involving a lawyer and advising him that he should engage his own lawyer, with obvious cost implications;

- I queried why the complainant was made a financial offer that would have covered the costs to take the exam in another country, but only if he withdrew the complaints.

\section{The Manifesto}

Around the same time that I became involved in the above case, in 2016 some TA colleagues published a Manifesto that likened the behaviours of refugees and politicians to playing psychological games. To me, this overlooked the realities of being bombed, raped, and having your children kidnapped. As Sedgwick (2021) explains, "a disproportionate amount of our clinical literature continues to be based on the sliver of individuals who have the means and willingness to pay privately for open-ended therapy. Few have seriously contemplated the possibility that theories based on work with affluent, educated, psychologically-minded, cultural-majority clients doesn't automatically generalise outwards to provide either a universal understanding of human experience or treatment practices...". (p.5). I remember protesting that murder and rape are not always psychological games - there are real victims!

The Manifesto was issued on behalf of the entire TA community, using the trademark three stacked circles. 
It claimed that politicians and refugees were playing a psychological game, as indicated in the following quotation: "We would like to see the situation we are in as a (psychological) game "hors catégorie" (Cornell et al., 2016). Hundreds of people-perpetrators and victims - have died. Thousands of people-again, perpetrators and victims-have been wounded. Millions of people-perpetrators and victims-are afraid. We are afraid. This fear creates a vicious circle (a game). It is time to do whatever is possible (to break this cycle.)" (p. 8). When I first saw a draft version of the Manifesto, I acted in line with TA Professional Practices and immediately challenged the originators direct but received no response. I was very concerned to see that a short time later it had become the official policy of ITAA and EATA, having been signed by the Presidents of both associations, and having been circulated by them. I was not aware of any consultation processes within those associations so I protested. The Manifesto was published on a website so I published an alternative website to host objections to it. Eventually the original website disappeared.

The Journal

This was followed in 2017 when I changed the nature of the International Journal of TA Research (IJTAR) to include Practice (IJTARP). I had been appointed Editor by EATA, launched the journal and had been the Editor since its inauguration in 2009. In 2012 I had attended as a guest an EATA Council meeting at which was submitted a proposal for a change of content of the journal to include Practice. The proposal had been cowritten by me and the EATA President at the time, my attendance and purpose was clearly shown on the Agenda, and I partially actioned the proposal in the following year with no apparent query. However, when in 2017 I actioned the decision more definitely (because it was a choice of that or no issue because we had insufficient research articles), I learned that someone within EATA Council had complained about the changes and that the Executive Committee had responded that it was my own decision and they had not discussed it. This was in spite of the fact that I had checked with them months before and they had approved the implementation of the decision. It was also in spite of the fact that this information had, as far as I knew, been circulated to the entire EATA Council before the meeting.

EATA Ethics Adviser subsequently suggested I could use an Organisational Complaint procedure. This procedure was not publicly available and did not appear on the EATA website until July 2020; there is still no indication of at which EATA Council meeting it was approved. The process began with the EATA President and Executive Committee at the time; during the process several individuals changed, although that did not appear to make any difference to the dynamics that played out.
The result of the complaint procedure was an Arbitration Report which contained numerous inaccuracies. The Arbitrator clearly believed that as an individual I was the same size of organisation as EATA, and that EATA ran like an organisation with paid employees. The Arbitrator decided that there were no records of the 2012 decision; after which it became clear that there were no records in Council minutes about anything linking the journal to EATA in spite of several EATA Presidents having signed fouryear contracts with me as the Editor. I pointed out many factual errors, such as stating that I had not made my complaint clear when that complaint was quoted elsewhere within the report However, no changes were made and, when I continued to protest, the EATA Ethics Adviser published the results on the Ethics Page of the EATA Newsletter and offered to provide a copy of the confidential report to anyone who requested it (redacted but obviously my name was known already). The Arbitrator placed a Binding Condition on EATA Council as well as on me; EATA Council have still not complied. They also failed to recruit a replacement Editor so that I stepped back into that role rather than see the work of the authors disappear. As you will see as you read this article, IJTARP still exists although without any support from EATA.

\section{World TA Conference}

In spite of my previous experiences, I agreed to lead the Organising Committee for the World TA Conference 2020 (WTAC2020). There was a very clear contract with six different TA associations about how this would be organised and how the profits or losses would be shared between those associations. We were well on track to have 1000 participants when coronavirus emerged during March 2020. The associations authorised us to organise an alternative online conference in case it should be needed. However, participants began to demand refunds of their booking fees and some of their money had already been spent on things like hotel deposits, IT and clerical support. We had been authorised by the UK-based associations to set up a limited company in the UK, to protect UKATA (UK Association for TA) from financial liability if something untoward happened that was not covered by conference cancellation insurance. We did this because previous TA conferences had been disrupted by terrorism and flooding, although we had no idea at the time that it would be coronavirus, nor that infectious diseases would not be covered by conference cancellation insurance.

After coronavirus emerged, at various times we requested emergency financial assistance of around $€ 30,000$ when EATA had $€ 300,000$ in the bank, we negotiated a postponement with the conference hotel that was supported by the majority of the participants 
and would have allowed us to give refunds to the others, and we were intending to provide a free online conference to participants and were receiving further bookings. At that point, five of the associations issued an announcement that the conference was cancelled. This was done in spite of the fact that they had authorised us, in writing, to negotiate with the conference hotel, and promised they would support whatever transpired. They had also authorised us to organise the online conference.

We had been doing all of that in spite of EATA President accusing me of playing a psychological game when I first requested assistance from the TA associations responsible. That accusation was never withdrawn. It was interesting that EATA President did this by circulating an email containing his agreement with a comment made by the Chair of the World TA Organising Committee ; when I queried this with that colleague the response was that it was a private conversation and he did not expect me to find out what he had said.

When the request for support was reiterated by the IDTA President, the other associations simply ignored her emails and subsequently IDTA was excluded from future decision-making by the other five associations with whom they had signed the contract. When the announcement appeared that the conference was cancelled, I was legally obliged under UK law to put the limited company into insolvency. When they then announced that the online conference no longer had their support, all keynote and several other speakers withdrew. The associations are now claiming that they protected the participants' money but in fact they reduced it because the insolvency specialists will have deducted for their time spent in meetings with this Creditors Committee, which cannot in any case change the strict UK law about insolvency.

\section{Punitive Elements}

During the Ethics Case, the punitive elements occurred during and just after the process ended. I was labelled a whistle-blower and threatened with TA 'excommunication' if I did not keep quiet. The complainant had by then walked away from the TA community so I kept quiet.

After many colleagues had supported my protest about the Manifesto, the Dutch TA Association cancelled their agreement with me to be the keynote speaker at their 40-year celebration, in an email sent by one of the originators of the Manifesto.

I have no way of knowing who has copies of the confidential Arbitration Report that resulted from my organisational complaint. However, the Ethics page in the EATA Newsletter is now available on www.academia.edu, which has 157 million registered users who can access the report about me that conflates an organisational complaint with an ethical issue.

Since WTAC2020 was cancelled, the associations continue to issue statements that give the impression that the loss of money to all participants is not because those associations cancelled the conference. ITAA President wrote that "I felt proud and moved at the most recent meeting with the presidents of all the responsible associations because everyone there reflected on what we could have done differently and how we could make conscious and unconscious meanings from the crisis. There was not a trace of defensiveness and scapegoating but rather a collective feeling of goodwill and determination to honour our responsibilities to the membership at large." (Leigh, 2020, p.5). Just before that, she wrote that she is "aware of the importance of you, the membership, feeling informed in ways that settle and satisfy you. When that is not forthcoming, it can become another shadow in our history that may render us vulnerable to further enactments." (p.5). There is no mention of any contact with the Organising Committee members or with the IDTA President, even though the article is headed Bonds That Hold Us Together.

At the time when cancellation was being threatened, I sent an email headed 'In Desperation', which is now included at the beginning of this article. You will see that I sent this to the decision-makers. Two days later I received a personally critical email from the German TA Association (DGTA). Two months later I received a very similar email from the Swedish TA Association (STAF). Some of the associations continue to issue statements. I estimated a long time ago that refunds via insolvency would be about $20 \%$ - they have been announced as $22 \%$. More information is available in the March 2021 IDTA Newsletter at http://www.instdta.org/uploads/1/2/3/8/12385375/idta news mar 2021.pdf. The log I was advised to maintain by the insolvency advisors as Director of the limited company can be seen at http://bit.ly/WTAC2020DirectorLog. I was the only director left because the original UKATA and IARTA directors accepted my offer to continue alone when we realise that insolvency might be needed.

There have been no responses so far to requests by others to conduct independent reviews, of the events with the journal or the conference.

\section{Psychological Games}

Although I will now describe some of the TA material about games, and related to the case examples I have described, I will be inviting you below to consider whether TAMED is really a psychological game or part of the systemic context of a professional association. 


\section{What Berne Wrote}

The first reference to the term 'games' seems to have appeared in Berne (1958), reproduced in Berne (1977) after the publication of several books by Berne and others. In that original article, Berne (1958) wrote that "Short sets of ongoing transactions may be called operations." and "A series of operations constitutes a "game." A game may be defined as a recurring series of transactions, often repetitive, superficially rational, with a concealed motivation or more colloquially, a series of operations with a "gimmick."' (p. 152 in Berne 1977). He illustrated this with a game of 'Yes, but...' being played within a therapy group, explaining that the gimmick "is that it is played not for its ostensible purpose (a quest for information or solutions), but for the sake of the fencing..." (p. 153) between the players as the one who is 'it' successfully objects to any solutions offered by the others. It would seem that the Presidents of the TA associations that cancelled WTAC2020 objected to many options, even after they had authorised the Organising Committee to undertake them (including the online conference) or to negotiate them (including the postponement until 2023).

In the same article, Berne refers to other common games and represents games with a transactional diagram that shows an Adult-Adult stimulus and response at the social level, and a Child-Parent interaction at the psychological level, using dotted lines for the latter. He also illustrates it in terms of therapeutic effect by showing a Parent-Adult contamination for those offering the solutions, which was resolved once the players became aware of the dynamics of the game. Later Berne (1961) used slightly amended diagrams to illustrate games, combining social and psychological levels into one diagram.

He also illustrated the gains from game playing, going on to amend this by the time he wrote Games People Play (Berne 1964) to be:

- external psychological advantage - as the avoidance of the feared situation;

- internal psychological advantage - maintaining the psychic economy such as avoiding experiencing neurotic fears and meeting masochistic needs;

- $\quad$ internal social advantage - a way of structuring time;

- external social advantage - the opportunity for pastiming with others;

- biological advantage - the parties stimulating each other and removing each other's isolation, explained in terms of strokes;
- existential advantage - the reinforcement of [life] position.

In 1961 he concluded with a section of Notes in which he commented that he had often been asked for a list of games, for which he had only a partial and provisional response. He went on to give several game names. In 1964 he provided details of a number of games under the headings of: life games, marital games, party games, sexual games, underworld games, consulting room games and good games. In between, in 1963 he explained the original technical meaning of gimmick as "a device placed behind the Wheel of Fortune so that the operator could stop it in order to prevent the player from winning. Thus it is the hidden snare which is controlled by the operator and assures him of an advantage in the pay-off. It's the "con" that leads to the "sting."” (p. 156). Note that this description conflates gimmick and con, reinforcing the notion that every party to a game has hooks like matching pieces of Velcro (Hay 2012) that join together so we cannot claim that someone else is playing a game with us as if we are not doing the same. Berne's metaphor of games being like roulette wheels implies that the operator and the player are both intending to take part in what follows, although it may be that the player believes the reputable casino does not have any gimmicks installed.

He defined a game in 1964 as "an ongoing series of complementary ulterior transactions progressing to a well-defined, predictable outcome. Descriptively it is a recurring set of transactions, often repetitious, superficially plausible, with a concealed motivation; or, more colloquially, a series of moves with a snare, or 'gimmick'." (p. 44). He differentiated games from procedures, rituals and pastimes by their ulterior quality and the payoff, adding that every game is basically dishonest and the outcome is dramatic rather than merely exciting. He added that a game looks like a set of operations superficially but that it becomes clear after the payoff that the operations were really manoeuvres. He gives the example of an insurance agent whose congenial participation may conceal a series of skilful manoeuvres aimed at eliciting information so that 'a killing' may be made. He emphasised that 'game' does not necessarily imply fun or even enjoyment, that 'play' is also serious, and that the grimmest game is 'War' - an interesting claim that resonates with Barnes (2004) (below) pointing out that Berne appeared to take little account of contextual circumstances.

Berne also distinguished games as:

"(a) A First-Degree Game is one which is socially acceptable in the agent's circle. 
(b) A Second-Degree Game is one from which no permanent irremediable damage arises, but which the players would rather conceal from the public.

(c) A Third-Degree Game is one which is played for keeps, which ends in the surgery, the courtroom or the morgue." (p. 57).

Again, an interesting conception that seems to imply that there is no permanent damage until the level is such that there are serious outcomes, again without any apparent consideration that a third--degree game outcome might also be the result of circumstances. This sequence of levels also seems to imply that games within the TA community around ethics issues are usually second-degree, although publication of the results moves it up but not as far as third-degree. It also seems that cancelling the conference so that UK legal requirements came into effect must be thirddegree, although we might think more degrees are needed as 'courtroom ' seems somewhat less serious than 'morgue'.

In the concluding chapters in 1964, Berne wrote that games are passed on from generation to generation, so that game analysis takes place in an historical matrix, and there is a strong tendency to inbreed with people who play a similar game - hence there is an historical significance of games. Raising children involves teaching them what games to play - which is the cultural significance of games, and games are ways of getting away from the boredom of pastimes without the dangers of intimacy - hence the social significance of games. The personal significance of games is that we choose as friends others who play the same games. Maybe he should have added that we choose our colleagues in a similar way?

Playing TAMED

In 2005 Graham Barnes (2004) was given the Eric Berne Memorial Award for pointing out that Berne believed that homosexuality was a game, with no account taken of the reality of the consequences of the cultural context. Aiken (1976) pointed out that telling gay and lesbian people they were playing 'Kick Me' when they were harassed was like saying the Jews were playing a game with Hitler. In the Manifesto those who signed it were accusing all refugees of playing psychological games with all politicians.

Jacobs (1977), who also received the Eric Berne Memorial Award, wrote in his acceptance speech: "The last idea I'd like to discuss briefly is the relationship between theory and ideology. Theories are developed to explain what we perceive. They remain theories until they are proved correct. What happens often is that in our haste to make the world a better place we parentize theory, make it a rule, a morality, the way things really are. And then we require that everyone adhere to this theory. When this happens we often exclude criticism of it; we exclude Adult information." (p.13). Claiming that someone else is playing a psychological game, within the TA community, makes it very difficult for anyone to challenge that perspective. We would not challenge it when they say it about a client, so we do not expect challenge it when they say it about a colleague.

I am introducing the game label of TAMED to describe situations when a TA professional accuses someone else of playing a game, particularly when they do that rather than announcing that they believe that they themselves are playing a game and they want to stop doing so. Announcing that someone else is playing a game sounds as if the professional somehow knows better than others about some very complex situations. For me, it comes across as if TA is yet another religion, where the followers of TA know better than anybody else what should be done to solve the problems of the world.

It is often accompanied by the frequent use of words such as 'we' and 'all', which seems grandiose, as does claiming that we have 'co-created'. Such comments about being in a psychological game reproduce the same bias that Berne had when he named a game as Rapo i.e. of making no allowance for the fact that women who are raped, and people who are unlucky enough to have been born in an area of the world where others decide to start wars, are not engaging in a psychological game. For me, being a civilian in Syria (or anywhere else where similar conflicts are occurring) does not mean automatically that you have a con or a gimmick, or that you engage in complementary ulterior transactions, or that there is a switch. For me, those caught up in areas of the world where there are conflicts are unlucky in the same sense that those in Japan and Ecuador are unlucky to be living in an area where there are earthquakes.

Writing of the aftermath of the Oklahoma bombing, Allen \& Allen (1998) wrote that: "While some people will complete drama triangles in their head, no matter how much we work to avoid this eventuality, would-be helpers can consciously and deliberately work to decrease the intensity and frequency of such phenomena." (p. 207). They added that "We humans seem to need some larger story to make sense of our experiences and into which we can integrate our own personal stories. Since the same event can fit into several different scenarios, each leading to different perceptions, explanations, and courses of action, the role of bystanders and especially of public officials and the media in creating these scenarios is especially worthy of careful study. It is important to support those that are more likely to lead to recovery and healing rather than those that are likely to lead to more suffering. It is troublesome, yet in a way liberating, to realize that any of several different scenarios may 
work equally well. They do not have to be truly valid, only feasible and meaningful." (p.208).

If we wish to apply a TA analysis to what is happening, I think we need to allow for the fact that some people just get caught up in events, albeit that others are acting in line with transgenerational scripts - either way, they need help rather than blame. Otherwise, we risk giving the impression that just thinking about, and reflecting on, TA concepts can somehow provide solutions to complex problems that non-TA people struggle with, now and for centuries past.

\section{The Bystander Role}

I believe also that the Bystander role is being misinterpreted. Jacobs (1987) was clearly not referring to those remote from events, when he wrote that "Bystanders watch others eat and are initially outside the development of Master/Follower. They are usually within the same system, be it national, religious or social. ... Often Bystanders are converted and become Followers; others feign conversion in order to avoid persecution." (p. 62).

Clarkson (1987) maintained this link to the actual events when she wrote that: "A Bystander is considered to be a person who does not become actively involved in a situation where someone else requires help. In the literature, the concept of the bystander is consistently applied to describe the behavior of people in emergencies such as the Kitty Genovese murder, where several people witnessed a violent assault without any effective intervention (Latané \& Darley, 1970). Where one or more people are in danger, Bystanders therefore could, by taking some form of action, affect the outcome of the situation even if they were not able to avert it. Thus, by definition, anyone who becomes actively involved in a critical situation, whether we describe this choice as pathological (script bound) or autonomous, is not a Bystander." (p. 82).

It is interesting to note that Clarkson shifts from Jacobs' focus on totalitarian cultures into events where the so-called Bystander is still actually present and could directly intervene - and that the Kitty Genovese story she quotes was subsequently exposed as a myth (http://digest.bps.org.uk/2007/10/truth-behindstory-of-kitty-genovese.html).

We need to be careful about how we label people as bystanders. In terms of the Manifesto and its comments about refugees, it might be interpreted to mean that if we were in Syria, or Nigeria, or wherever else people were being hurt, and then we did do nothing, we were (probably dead!) Bystanders. I would have thought that Clarkson's comment about affecting the outcome through some form of action means that those who have elected governments that provide aid from their citizen's taxes, or those who donate personally to charities are not Bystanders and are not in a psychological game.

Perhaps we are Bystanders when we discount the reality situation and ignore the plight of refugees. The publication of the Manifesto on an international TA forum, to which I added comments, prompted a TA colleague to write that: "I think, what the refugees are playing, if any, is, that they are in their habitual behaviour (what else should they know? and ask for help: not suggest solutions,) and that is perceived as threatening in a territorial way. And what they also contribute is, that they pay people, to bring them over illegally and unofficially, before they asked for a place to stay - and this translates badly culturally: we take public or private transport and come across borders with valid papers - hotel booked - why not them? And why do they have the money and want help from us? Why should we share our little goods (if we are poor) with them? So that in my view, this can be called a game (with overt and covert aspects). And for switches: Now I got you; I am only trying to help you; You are so wonderful....?"

My response to this was "I think if someone bombed my home or was forcing children like mine into sexual slavery or to be a child soldier, I would not wait to ask someone I don't even know in another country, and whose language I may not know also, if it was alright if I came to their country - I would gather all the money I had, or could get sent to me by relatives or friends who had escaped previously, to get to somewhere where I hope to be safe. I think we should beware of talking of games to explain why good things happen to bad people and bad things happen to good people."

In terms of outcomes of the publication of the Manifesto, the comments above about refugees staying in their bombed cities until they are invited to travel to safety seems to me to lead to more suffering. In this way, it could be seen that the bystanders signing the Manifesto are the ones who are conjuring up drama triangles in their heads.

I think that the definition of being a bystander is incomplete - it should say something about being a person who has the power to take appropriate action but does not become involved when someone else needs help. Otherwise, everyone in the world is a bystander if they do not become involved in the various conflicts and natural disasters. There are many, including within the TA community, who are taking action within their own power to do so in various situations. Ironically, we need the word 'appropriate' in the definition (although it is probably impossible to know whether something is appropriate or not without the benefit of historical hindsight) because there are many who are taking actions that others criticise - the authorities cannot be considered to be bystanders 
even though some may believe that what they are doing is making things worse.

\section{Potency Pyramid or Drama Triangle}

I suggest that another way for us to consider what is happening, before we accuse someone of playing a psychological game, is to check out whether they are operating within the drama triangle (Karpman, 1968) or the potency pyramid (Hay, 2009).

When Karpman introduced the drama triangle, he stated that only three roles were necessary to depict the dramatic emotional reversals that come with switches in the roles. He used stories, such as Little Red Riding Hood starting as Rescuer, becoming Victim to the Wolf Persecutor, who in turn becomes Victim to the woodsman Persecutor, who also Rescues Little Red Riding Hood and grandmother; with a further example of the Pied Piper, where the hero begins as Rescuer of the city and Persecutor of the rats, then becomes Victim to the Persecutor Mayor who refuses to pay the fee, and then switches to Persecutor of the city and its children. The mayor moves from Rescuer when hiring the Pied Piper, to Persecutor and then to Victim when the children are dead. The children switch from Victims being Persecuted by rats, to Rescued Victims by the Pied Piper, and finally to Persecuted Victims. Of course, if these fairy stories were true, then no game is being played.

Karpman gives a similar account of the story of Cinderella, indicating that counting the number of switches in a story will give a rough quantitative analysis of the intensity of the drama. However, he points out that games are simpler and have only one major switch, or one major rotation around the drama triangle.

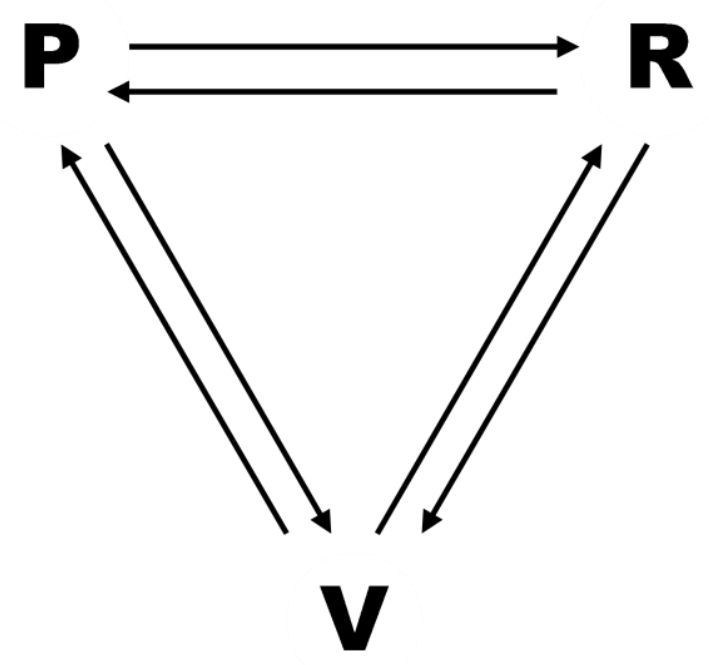

Figure 1: Drama Triangle (Karpman 1968 p. 40)
English (1976) suggested that Karpman's drama triangle incorporated two types of Victim. She linked this to her material on racketeering and said that a Type I opts for a payoff as Persecutor whilst a Type II racketeer stays in Victim role. To illustrate this, English drew two overlapping triangles so that there were two Victim Points with one Persecutor and one Rescuer. She pointed out that Type I Victims are easier to spot because they begin as Victims and later switch, whereas Type II Victims appear to be competent and do not become apparent Victims until they are 'kicked'. Hence practitioners need to be most concerned about those who spend the least amount of time as Victim.

As already mentioned, Clarkson (1987) proposed that the role of Bystander, or audience, needed to be added to the context of the drama triangle. She drew several semicircles below the triangle, which looked as if it could be the rows of seating for the audience at a theatre. In addition to the Bystander having a negative connotation such as passive collusion or turning the other way, Clarkson pointed out that such people could also be witnesses. Clarkson (1993) went on to suggest examples of what she called Bystander games, such as 'It's more complex than it seems ', or 'I don't have all the information'. EATA President has refused the request for an independent investigation into the conference cancellation process "because of the complexity of the topic and the clarity of such an investigation instrument" (Rudolph, 2020, p.3). He suggests instead the option of involving professional conference organisers.

Choy (1990) suggested that we might use what she called the Winners Triangle to teach an antithesis to the Karpman Drama Triangle. For this, she converted Karpman's diagram into a simple triangle and changed the labels to be Assertive, Caring and Vulnerable. She suggested that Assertive people ask for what they want, say no, give feedback, negotiate and make changes to get their needs met; Caring people do not think for others or take over unless asked and they want to, do no more than their share and do not do things they do not want to do; Vulnerable people use Adult ego state for thinking and problem-solving and awareness of their feelings as data.

I suggested a similar idea which I referred to originally as the Autonomy Triangle (Hay 1995) and later renamed as the Potency Pyramid (2009), reversing the direction of the triangle so that the visual impact would be different. I also used words that matched the initial letters of Karpman's original labels, substituting Powerful, Responsible, and Vulnerable whilst pointing out that the combination of these three led to Potency. I have described these (Hay, 2009) as "Powerful being appropriately powerful, taking action when we 
should, including on behalf of genuine victims who cannot help themselves; Responsible - taking responsibility only for those things that are truly ours to deal with and not taking over other people's responsibilities; Vulnerable - displaying our own vulnerability and asking for help when we need it whilst accepting that others have the right to refuse our request." (p. 153).

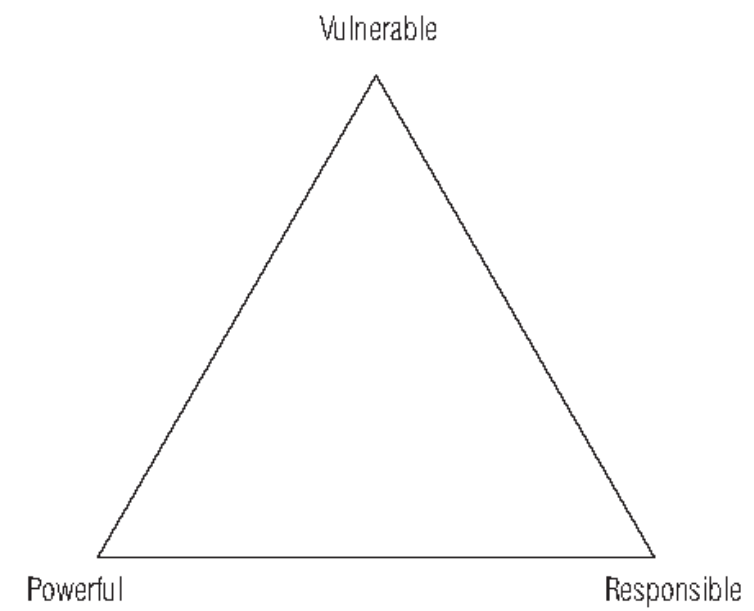

Figure 2: Potency Pyramid (Hay 2009 p. 150)

I believe I was openly Vulnerable when, on behalf of the Organising Committee, I asked for support when coronavirus emerged. The leaders of the five associations denied that they were Responsible in spite of the contract about profits and losses. They were Powerful enough to have decided to provide the support that was being requested. I learned later through the UK Companies House that UKATA and IARTA had enough money in the bank, and EATA Treasurer had been announcing at General Assemblies that EATA had too much money in the bank for a professional association based in
Switzerland. IDTA had already made it clear that they would go bankrupt because their funds were small but they were willing to provide as much financial assistance as possible.

In their material on symbiosis, Schiff and Contributors (1975) and collaborating authors referred to three types of redefining relationships which provide us with another way of understanding the way in which Berne describes game dynamics in terms of transactions :

- Symbiotic, for which they show a transactional diagram with an overt interaction between a Child contamination of Adult in one person and a Parent contamination of Adult in the other person, and an ulterior transaction between the respective Child and Parent ego states.

- $\quad$ Parent-Competitive, for which they show the overt transaction as between two Parent contaminations of Adult and the ulterior transaction as between the two Parent Ego states. In this, "Both people attempt to get the other to over-adapt to their definition of the situation, issue, or event.... The strokes may be positive or negative, and the people may occupy any one of the three positions on the Karpman Drama Triangle. However, they usually attempt to occupy the same game position at the same time." (p. 63)

- Child-Competitive, which is similar to the ParentCompetitive but now the transactions are between Child contaminations of Adult and at the psychological level between the two Child ego states. "The favoured positions... appeared to be Victim and Persecutor, and both people usually attempt to occupy the same position simultaneously. The most intense competition tends to develop around the Victim position." ( $p$. 64).

\begin{tabular}{|l|l|c|c|}
\hline \multicolumn{1}{|c|}{ Hexagon Role } & \multicolumn{1}{|c|}{ Typical Game } & Social Level & Psychological Level \\
\hline Hard Worker & Look how hard I'm trying & Rescuer & Victim or Persecutor \\
\hline Caretaker & I'm only trying to help you & Rescuer & Victim or Persecutor \\
\hline Angry Righteous & $\begin{array}{l}\text { Gotcha (called by them } \\
\text { NIGYSOB) }\end{array}$ & Persecutor & Victim \\
\hline Woeful Righteous & $\begin{array}{l}\text { Look what they're doing to me; } \\
\text { Ain't it awful }\end{array}$ & Persecutor \\
\hline Angry Wrongdoer & Kick Me; Kick Me (If You Dare) & Victim & Persecutor \\
\hline Woeful Wrongdoer & $\begin{array}{l}\text { Poor Me; Kick Me (Please!); Don't } \\
\text { Kick Me (Please?) }\end{array}$ & $\begin{array}{c}\text { Persecutor but } \\
\text { then into Victim }\end{array}$ & Victim \\
\hline
\end{tabular}

Table 1: Summary of Roles (based on Schiff \& Contributors, 1975) 
- However, they appear to make the same jump between levels as Berne did; their explanation of how game shifts are achieved through one of the four passive behaviours appears to jump from doing nothing, over-adaptation, agitation - which all may have little direct physical impact on other people, up to incapacitation or violence, which seems restricted to physical impact. Where would we fit outcomes such as organisational disciplinary processes, financial penalties, reputational damage - and even game outcomes that invite others to ostracise one of the players?

Schiff et al also suggested that there were six roles rather than three, showing these on what they called the Redefining Hexagon, using labels that need little explanation, and pointing out that the social level is generally different to the psychological level, which is the position that person is intending to occupy, defending against, or occupying at a hidden level. Table 1 summarises some of their examples.

During the dynamics that led to the cancellation of the conference by the five associations, there did not appear to be any Rescuer at the social level. We might see the negotiation of the postponement as Rescuing but that would require us to regard those who had booked to attend as Victims, which would imply that they knew when they booked that the conference might get cancelled and were accepting that it was a gamble.

Some years later, Summerton (1992, 1993a) introduced what he called the Game Pentagon, changing the names for Karpman's three roles and adding two more roles, as a tool for analysing games from the external point of view rather than from an internal and interpersonal perspective. His five roles are illustrated in Figure 3:

Stage Manager - the originator or source of an event, who unconsciously sets up the scenario or consciously masterminds it - such individuals may be forgotten because they do not appear on the scene of dramatic events. Perhaps this applies to the Chair of the World TA Conference Committee when he advised EATA President that I was playing a psychological game.

Spectator - the audience, the one who sits back and appears to be uninvolved but provides support by appearing interested in the event. Presumably this might apply to the members of the Boards/Councils of the TA associations involved, who made no attempt to ascertain the facts and simply supported their leaders.

Sniper - the openly decisive person, who may attack, defend, protect or prune, and offers critical comments and put-downs. There seemed to be several of these, including EATA Ethics Adviser and the Presidents of the two TA associations who wrote to me afterwards.
Saviour - the ombudsman who brings justice, saves others from harm, takes up social causes. Maybe this is part of the role of this author, who allowed the other directors to maintain a low profile when it became clear that the company set up to run the conference might have to stop trading.

Scapegoat - who bears blame for others or suffers consequences on behalf of the group. Clearly this author, in an extremely high-profile manner.

Summerton comments that Persecutor, Rescuer and Victims fit into Sniper, Saviour, and Scapegoat. The Connection (Steiner 1971) might be Stage Manager, and the Spectator may be the audience referred to by Karpman (1968).

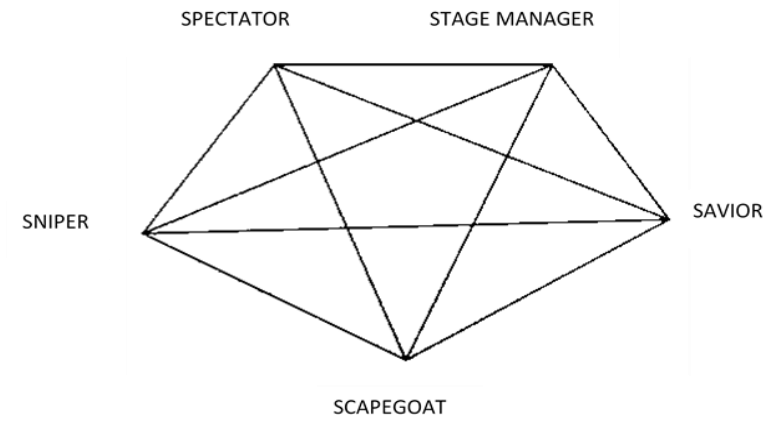

Figure 3: Game Pentagon Summerton 1992 p. 69

\section{So why do TA Professionals play TAMED}

We can add to our understanding of these processes by considering some ideas on how conflict and bullying play out within organisations, and hence within associations.

Non-TA author Totton (2000) reviewed the interaction of politics and psychotherapy, quoting Cooper (1976) for defining politics as "to do with the deployment of power in or between social entities" (p.4). I have already mentioned the power dynamics built into TA associated with our structure of qualifications. I recall the horror expressed by some TA colleagues when I pointed out that TA operates as multi-level marketing - trainees purchase from PTSTAs and PTSTAs purchase from TSTAs. To this hierarchical aspect, we can add the vestigial prejudices that maintain the myth that 'clinical' (i.e. psychotherapy) has a higher status than the 'special fields' (i.e. educational and organisational applications of TA, with the status of counselling varying in different countries).

Totton also alerts us to how psychotherapists demonstrate an "above-average degree of argumentativeness. We have seen therapists adapting with greater or lesser success to the demands of totalitarian regimes; competing viciously with each other for power, prestige and income; and manipul- 
ating institutions and training programs in order to maintain hegemonic control." (p.133).

He goes on to comment on how we use transference in our work, which means that the strong feelings in the client towards the practitioner leave a residue within the practitioner. This is likely to be carried into their contact with colleagues within professional organisations. Hence, negative interactions with colleagues may be the release of negative emotions stimulated by clients. Cornell (2020) describes how Berne (1947) had a similarly pessimistic view about leaders and followers generally, suggesting that leaders are likely to be power-hungry Egotists leading Ego-Searchers who want to lean on a stronger personality and Egocentrics who want approval. According to Berne, the leader simplifies things for their followers.

Dalal (2016) described a similar process within the psychotherapy community itself. In an article based on a presentation he had made at an ITAA conference in 2015, he challenges the common view within psychotherapy that the source of all social dynamics, and particularly the difficulties, are attributed to internal psychological dynamics within individuals. He invites us to consider, for example, how hateful feelings come to be directed to particular groups, based on factors like skin colour, race or religion, if such hate is inherent within an individual. He also writes of tyrants punishing those who challenge them by making them outcasts, commenting that some of his colleagues did that to him when his first book did not match those colleagues' concepts.

He concludes that "The belief that the internal psychological world is the source of our experiential world has a tyrannical grip on our mindset in this profession ... the dominant discourses determine not only what we are able to see but also what we think about it that makes it a tyranny. Ruling paradigms bind us to the normative unconscious and blind us to the existence of alternative possibilities. ... the orthodoxy in our profession thinks it to be an error, an acting out, on the part of the therapist." (p.98).

Another non-TA author, Eddy (2019), provides insights as to why elected leaders are often narcissists and sociopaths. His comments include how:

- high-conflict politicians (HCPs) are elected because four groups of voters fight with each other, labelling the groups as Loving Loyalists who will do anything for the leader, Riled-Up Resistors who oppose the HCP, Mild Moderates who ignore the character defects of the HCP, and Disenchanted Dropouts who don't bother to vote.

- HCPs maintain their positions by inventing 'fantasy crisis trials 'in which the 'voters' need the leader to defeat the 'villain' - in TA-speak, the
Victims need the leader to Rescue them by Persecuting the would-be evil Persecutor.

Eddy explains that HCPs cannot help how they are, which is the result of genetics, early childhood experiences, and the cultural environment. - in TAspeak, no surprises there.

However, HCPs create 'targets of blame', who will struggle to understand what is happening to them because the HCPs are seductive, and skilled at using 'splitting' so people see others as all good (i.e. the HCP) or all bad (i.e. the target, whoever they are).

Targets of blame need to be:

- familiar to the voters so they need no introduction;

- not part of voters' daily lives so they have little knowledge of what the actual behaviours are;

- $\quad$ widely viewed as powerful even though they are not compared to the HCP;

- already the target of resentment, which is especially effective if the resentment can be about the target's achievements so voters feel envious;

- seen as connected to secret power, for which the leader may invent conspiracy theories.

Although Eddy went on to write about Hitler and similar dictators, we can see how an individual can become a target of blame within any community. He wrote that "It's rarely about thoroughly examining the facts and honestly reporting that many of these alleged crimes are actually non-existent - or are problems that are already being or can be well-managed or solved." (p.119).

We can consider Eddy's material in terms of that written many years before by Jacobs (1991), based again on Berne's (1963) material about organisations. Jacobs writes of autocracy, applying this to any collection, from two people, through groups and organisations, to complete nations. He refers to Masters and Followers, with a permanent life position of I'm OK, You're not OK towards Dissenters. He suggests we consider the degree of autocracy based on who is suppressed: "those who disagree in an organised way, those who disagree individually, those who might disagree, or those whose agreement or disagreement makes no difference." (p.204). Thus Jacobs also points out that democracies have canons that limit the actions applied to dissenters whereas autocratic cultures will use the internal and external apparatus against them. With TA associations, these mean processes such as what gets published (newsletters, websites) as well as actions taken by role-holders.

Another factor was identified by non-TA author Chown (2020), who conducted an ethnographic field study into 
how a new behavioural control mechanism was introduced into a teaching hospital in Canada. This too can be understood using a TA framework. Chown pointed out that designing such controls are particularly challenging when they are about work done "by professionals with high autonomy and considerable discretion." (p.64). What Chown found might also be understood if we consider Laugeri's (2006) model of emerging change that is based on Fox's (1975) chart that summarised Berne's (1963) material about organisations. Such changes are typically considered to be introduced in a top-down manner, whereas Chown, and Laugeri, indicate how much of it is generated in a bottom-up manner as those actually doing the work adapt the new controls to the circumstances. Chown refers to "two pathways in the co-creation of controls, which I call customization and transmutation. In the first pathway, they customized the design of the mandated control mechanism so that it functioned well in the context and achieved its intended control outcomes. In the second pathway, they developed their own locally designed alternative control mechanisms to achieve the intended control outcomes and then abandoned the mandated control mechanism." (p.74) (italics in original). We might speculate how much it is possible to introduce top-down control designs within a TA association.

Yet another perspective was provided by Timmermans (2020), whose article was published in the Transactional Analysis Journal towards the end of the year in which the associations cancelled the conference. She proposed that workplace bullying should be regarded as due to an organisational script. Quoting research studies that indicate that up to a third of people surveyed (in UK and USA) had experienced such bullying, she goes on to quote:

- Krausz (1993) for linking life positions to exploitative, manipulative or dependent relationships, mentioning factors including competition and limitations on personal contributions;

- Summerton (1993b) for linking group games to the etiquette and technicalities of the culture;

- Clarkson $(1987,1993)$ for regarding Bystanders as an essential audience to keep the game going;

- Mohr (2012) for noting that the patterns remain within the organisation even though the individuals may be interchangeable.

Another useful explanation of why TAMED occurs is provided by Sills (2003). Building on the concept of role lock (Bogdanoff and Elbaum 1978), she writes of how the group leader may be unconsciously 'not allowing' issues to be owned by the group. She provides an example of a group member repeatedly raising issues and the "group itself firmly refused to understand or acknowledge that there might be any truth in [the individual's] ideas. Almost aggressively, they denied absolutely his perceptions - not only [specific members] but also all the other members who had allowed themselves to be led and guided." (p.285). Sills also described an example where the leader felt vulnerable to criticism. In that case, the group saw itself as 'a nice group', with a pattern of one member emerging as 'the difficult one' who would have arguments and then leave the group. That member would be told by the group that he was failing to behave in a suitably TA-based OK-OK manner and therefore owned the problem.

She concludes that role lock means that the 'difficult' one is raising their own script issues in a group that is denying their own issues. However, at the risk of engaging in SPOT, I suggest that it may well be that someone with many years of experience within the organisational field of TA may be identifying genuine problems that need to be addressed. I began this article with an example from my childhood about being blamed for something that existed within the 'group' that was my parents. I have known since I first learned TA in 1975 that they created me so they could place the blame elsewhere. Perhaps Sills needed to differentiate between deterministic and developmental scripts (Hay, 2012), or what English (1988) referred to as improvisation theatre.

To quote Sills' final comment, the 'role-locked' individual "brings the gift of potential awareness and growth to the whole group." (p.287). It is my hope that this article will reinforce Sills' message and challenge the TA myth of explanatory depth - sometimes a cigar is just a cigar and sometimes a dynamic is not a psychological game, as I will explore next.

\section{Is TAMED a Game?}

I mentioned above under Contextual Considerations that I have been noticing several articles in the TA literature that seem relevant to this theme. Several of them appeared in The Transactional Analyst, which is published by the UK Association for TA (UKATA).

Napper (2021) directly challenges looking at the systemic nature of bullying in society through a Persecutor-Victim model. Napper refers to Jean Illsley Clark explaining at a conference in 1996 that considering bullying as something on the drama triangle was to misunderstand Berne and the unconscious nature of games. Clark pointed out that bullies know they are bullying, even though the origins of the behaviour may be unconscious. Napper emphasises that viewing such issues through an individual lens means we may overlook the systemic causes; instead we need to consider "the existential 
and psychological levels of societies, both conscious and unconscious." (p.15).

Napper also refers to her decision to leave UKATA (one of the associations involved in cancelling the conference) after 25 years of membership because of the conscious, persistent references to psychotherapists instead of practitioners, which she regards as bullying, or 'othering', of the other fields of application.

In the same journal issue, Siddique (2021) points out how the traditional apprentice training model within TA is "in danger of (re) creating a hierarchical space for manipulation of trust ... [and that] ... It is important to hold onto their own narrative and call out bullying and discrimination...". (p.46).

Simpson writes that bullying seems to her "to encompass the whole range of forms of the misuse of perceived and actual power and authority. (p.4). Although the article is about how we can use TA resources to support those being bullied generally, she points out how "our own groups and TA organisations are not free from these dynamics. It is important that all transactional analysts nurture the willingness to open space for discussion and challenge, to be able to hold the discomfort of conflict rather than to turn a blind eye for an 'easy life'. I believe such healthy aggression and openness needs to be a more acceptable part of our culture." (p.5).

Finally, in the same issue we can consider some of the content of William's (2021) Keynote at the TA Cumbrian Conference, when he queried the impact on connection of our cultural stories. He refers to Booker (no reference given but presumably 2004) for story archetypes that include overcoming the monster, seeing this as a potential rationale for Berne's ideas of the pathology of clients being the big bad monster, so that our "job is to demonstrate dominion and oppression within a competitive frame." (p.43). Williams extends this idea to reflect on 'hostile architecture' (Rosenberger 2017), "which results in the alienation of the vulnerable individual" (p.43). He suggests we consider how TA may act as the oppressor, the negative editor, editing out those more vulnerable and less powerful." (p.43).

\section{The Organisational Perspective}

This concluding section is included at the suggestion of one of the reviewers of my article. I thank them for prompting me to begin the process of creating a new model for illustrating professional associations. The following are my initial thoughts - and I welcome feedback in order to develop the model further.

I conclude with some ideas about how we might consider TAMED as a manifestation of systemic dynamics that arise because of the nature of a professional association. I am prompted to do this also because of another theme that is emerging within the TA community - how EATA and ITAA can work more closely together. The current ITAA President (Leigh 2019) announced a personal longing for ITAA and EATA to reconnect, and how she felt some responsibility because she was on the ITAA Board when the affiliation formed in 1989 between those two associations was ended in 1995. More recently, both ITAA and EATA Presidents (Leigh and Rudolph 2021) have described the ending as "an important systemic intervention that facilitated the richer autonomous functioning of each association." (p.1). They go on to add that they intend to discuss this with past presidents. As the EATA President who concluded the negotiations to set up the Affiliation Agreement (which included Canada and India) and who then became the ITAA President in the following year and made every effort to implement the Agreement, I will be able to tell them how disappointed I was when the Agreement was abandoned a few years later.

I suggest also that we need to update the way in which we think about organisations that are professional associations. I have already extended Berne's organisational diagrams to develop the organisational cone (Hay 2016), as shown in Figure 4. In this I have taken Berne's (1963) two-dimensional circles and presented them in the shape of a three-dimensional cone.

This allows us to see that the leadership is in touch with the external world of the organisation and is not contained within the circle of the membership. It also reflects the hierarchical nature of any but the smallest organisations, with functional divisions that begin at the customer/client facing end of the organisation and continue up through the levels of management. Different groups within the organisation can then be shown to have different contacts outside the organisation. There are the employees who are in contact directly with customers, middle level managers and executives who are in contact with other organisations such as suppliers, and top-level management who deal with government officials, financiers and shareholders.

However, in a professional association maybe we may need something closer to Berne's original twodimensional diagram. As shown in Figure 5, the leaders are usually elected by the members so can be represented within a circle that exists within the wider circle of the membership. Funding comes from the members so there is no need for top managers to be in contact with financiers or shareholders. In their roles as officers of the professional association, they have no contact with clients. Figure 5 therefore illustrates a typical association that might be affiliated to EATA. 

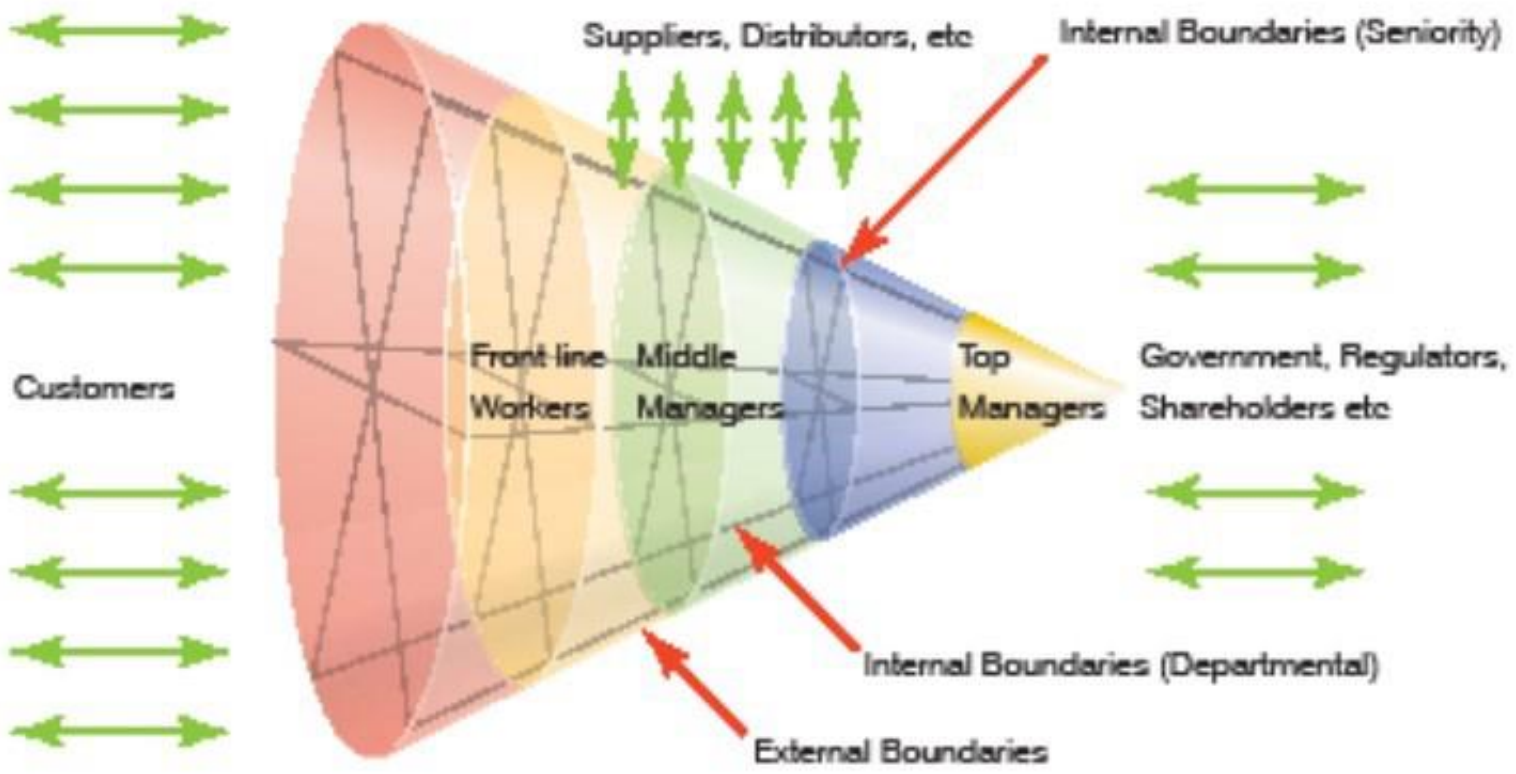

Figure 4: Organisational Cone (Hay, 2016, p.20)

Members elect their own executive committee, or board, or council, depending on which term they use.

I have then included a diagram to represent EATA Council. This follows the same pattern except that the 'members' of the Council are the delegates and they appoint the leaders. Each delegate is therefore representing a national association, or in some cases more than one when these exist within the same geographical boundary. I have included within the diagram several of the diagrams to represent the affiliated associations (not all of them - just enough to illustrate the point). This is because the delegates are there on behalf of their associations - they are not there in their own right as individuals. It is important to note that they are called delegates and not representatives; this is because they commit the associations who send them to any decisions that are made within the Council. They must therefore ensure that whatever they vote for reflects the views of the members within the associations who appointed them.

Figure 5 is an initial attempt to illustrate the structure and boundaries of EATA Council. It is important to note that there is no hierarchy in the way that exists in typical organisations. Unlike employees who may expect to follow the instructions of their managers, the members of professional associations choose their own leaders and expect them to fulfil the wishes of the members. For such an association, it is as if the hierarchy has to be drawn upside down. The association belongs to the members, who are therefore bystanders if they take no action when their leaders play psychological games.
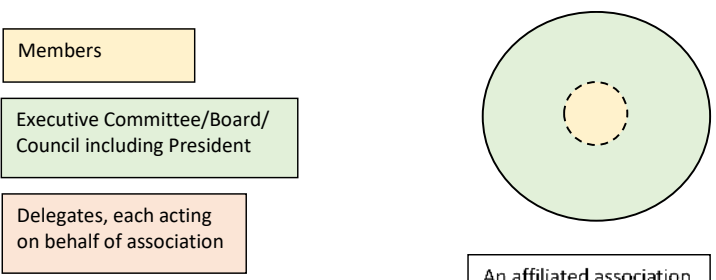

An affiliated association

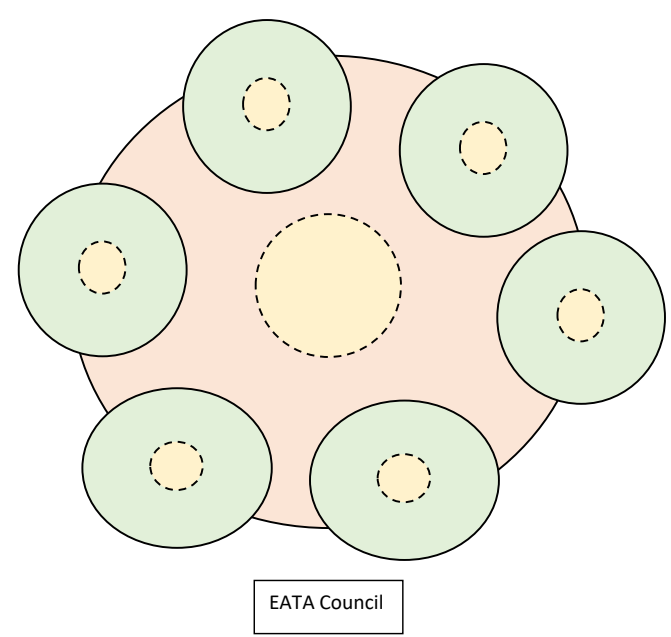

Figure 5: An Illustration of EATA Council 
It has been many years since I was EATA President. The EATA Council used to meet three times every year and the role of the Executive Committee was only to deal with anything urgent that occurred between meetings. We did not have the option of emails or meeting on Zoom in those days.

A proposal was approved at the EATA Council meeting in 2020 that the Presidents of the Affiliated Associations could begin to have their own meetings. This is an intriguing initiative and it will be interesting to see how such a body will run alongside the EATA Council, when EATA Council consists of all of the associations that have appointed those presidents.

Julie Hay is a Teaching \& Supervising Transactional Analyst (Counselling, Organisational, Psychotherapy, Educational). She is a past president of ITAA and EATA, a founding member of IDTA, Editor of IJTARP, Project Manager of the TA Proficiency Awards (www.taproficiencyawards.org), founding member of the International Centre for TA Qualifications (www.ictaq.org) and of the World Online TA Association (www.wotaa.org). She can be contacted on julie@juliehay.org.

\section{References}

Aiken, B. A. (1976). The Stroke Economy and Gay People. Transactional Analysis Journal, 6(1), 21-27. https://doi.org/10.1177/036215377600600107

Allen, J. R., \& Allen, B. A. (1998). Transactional Analysis Notes from Oklahoma City: After the bombing. Transactional Analysis Journal, 28(3), 202209. https://doi.org/10.1177/036215379802800303

Barnes, G. (2004). Homosexuality in the First Three Decades of Transactional Analysis: A Study of Theory in the Practice of Transactional Analysis Psychotherapy. Transactional Analysis Journal, 34(2), 126-155.

https://doi.org/10.1177/036215370403400205

Berne, E. (1947). The Mind in Action. Simon and Schuster.

Berne, E. (1958). Transactional Analysis: A New and Effective Method of Group Therapy. American Journal of Psychotherapy, 12(4), 735-743. https://doi.org/10.1176/appi.psychotherapy.1958.12.4 .735

Berne, E. (1961). Transactional Analysis in Psychotherapy. Grove Press.

Berne, E. (1963). The Structure and Dynamics of Organisations and Groups. Grove Press.

Berne, E. (1964). Games People Play. Grove Press.

Berne, E. (1977). Intuition and ego states: The origins of transactional analysis. TA Press.
Bogdanoff, M., \& Elbaum, P. L. (1978). Role Lock: Dealing with Monopolizers, Mistrusters, Isolates, Helpful Hannahs, and Other Assorted Characters in Group Psychotherapy. International Journal of Group Psychotherapy, 28(2), 247-262.

https://doi.org/10.1080/00207284.1978.11491610

Booker, C. (2004). The Seven Basic Plots: Why We Tell Stories. Bloomsbury.

Chown, J. (2020). The Unfolding of Control Mechanisms inside Organizations: Pathways of Customization and Transmutation. Administrative Science Quarterly, 41, 61-89. https://doi.org/10.1177/0001839220980015

Choy, A. (1990). The Winner's Triangle.

Transactional Analysis Journal, 20(1), 40-46. https://doi.org/10.1177/036215379002000105

Clarkson, P. (1987). The Bystander Role.

Transactional Analysis Journal, 17(3), 82-87. https://doi.org/10.1177/036215378701700305

Clarkson, P. (1993). Bystander Games. Transactional Analysis Journal, 23(3), 158-172.

https://doi.org/10.1177/036215379302300307

Cooper, D. (1976). The Grammar of Living. Penguin.

Cornell, B. (2020). How do Evil men gain followers? How does an evil leader hold his followers. The Script, July, 5-7.

Cornell, W., De Graaf, A., Newton, T., \& Thunnissen, M. (2016). Into TA: A Comprehensive Textbook on Transactional Analysis. Karnac. https://doi.org/10.4324/9780429476143

Dalal, F. (2016). The Individual and the Group: The Twin Tyrannies of Internalism and Individualism. Transactional Analysis Journal, 46(2), 88-100. https://doi.org/10.1177/0362153716631517

De Graaf, A. (2016). People Don't Kill People: TA Manifesto. The Script, June, 7-9.

Eddy, W. (2019). Why We Elect Narcissists and Sociopaths - And How We Can Stop. Berrett Koehler.

English, F. (1976). Differentiating Victims in the Drama Triangle. Transactional Analysis Journal, 6(4), 384-386.

https://doi.org/10.1177/036215377600600406

English, F. (1988). Whither Scripts? Transactional

Analysis Journal, 18(4), 294-303.

https://doi.org/10.1177/036215378801800404

Fox, E. (1975). Eric Berne's Theory of Organisations. Transactional Analysis Journal, 5(4), 345-353. https://doi.org/10.1177/036215377500500404 
Gregg, A., Mahadevan, N., \& Sedikides, C. (2017). The SPOT Effect: People Spontaneously Prefer their Own Theories. Quarterly Journal of Experimental Psychology, 70(6), 996-1010. https://doi.org/10.1080/17470218.2015.1099162

Hay, J. (1993). Working it Out at Work Understanding Attitudes and Building Relationships. Sherwood Publishing.

Hay, J. (1995). Donkey Bridges for Developmental TA. Sherwood Publishing.

Hay, J. (2009). Transactional Analysis for Trainers (2nd edition). Sherwood Publishing.

Hay, J. (2012). Donkey Bridges for Developmental TA (2nd edit). Sherwood Publishing.

Hay, J. (2016). Hay's Organisational Cone. IDTA Newsletter, 11(4), 19-20.

Jacobs, A. (1987). Autocratic Power. Transactional Analysis Journal, 17(3), 59-71.

https://doi.org/10.1177/036215378701700303

Jacobs, A. (1991). Autocracy: Groups, Organisations, Nations and Players. Transactional Analysis Journal, 21(4), 199-206.

https://doi.org/10.1177/036215379102100402

Jacobs, A. (1977). Psychodrama and TA. In M. James \& Contributors, Techniques in Transactional Analysis (pp. 239-249). Addison-Wesley Publishing Company.

Karpman, S. (1968). Fairy tales and script drama analysis. Transactional Analysis Bulletin, 7, 39-43.

Kets De Vries, M. F. R. (2021). Our Addiction to Charismatic Leaders Needs to Stop. https://knowledge.insead.edu/blog/insead-blog/ouraddiction-to-charismatic-leaders-needs-to-stop16676\#comment-60976

Krausz, R. (1993). Organisational Scripts. Transactional Analysis Journal, 23(2), 77-86. https://doi.org/10.1177/036215379302300205

Latané, B., \& Darley, J. M. (1970). The unresponsive bystander: Why doesn't he help? Appleton-Century Crofts. https://doi.org/10.2307/2063973

Laugeri, M. (2006). Transactional Analysis and Emerging Change, the Keys to Hierarchical Dialogue. In G. Mohr \& T. Steinert, Growth and Change for Organizations (pp. 374-395). ITAA.

Leigh, E. (2019). Intention: Unconscious or Conscious, the Results Live On. The Script, December, 5-6.
Leigh, E. (2020). Bonds That Hold Us Together. The Script, September, 5-6.

Leigh, E., \& Rudolph, P. (2021). Developing TA Now. The Script, 51(6), 1-3.

McGuinness, C. (2021). The Society is at a crossroads. The Psychologist, 34, 4-5.

McKinnon Fathi, N. (2017). Gaslighting: is this who we are? The Transactional Analyst, Autumn, 29.

Minikin, K. (2021). Relative Privilege and the Seduction of Normativity. Transactional Analysis Journal, 51(1), 35-48.

https://doi.org/10.1080/03621537.2020.1853349

Minikin, K., \& Rowland, H. (2020). TAJ Theme Issue on Systemic Oppression: What Part Do We Play. The Script, September, 9.

Minikin, K., \& Rowland, H. (2021). Call for papers "Systemic Oppression: What part do we play?". The Transactional Analyst, 49.

Mohr, G. (2012). Pattern theory as a meta perspective for change. Transactional Analysis Journal, 42(2), 134-143.

https://doi.org/10.1177/036215371204200207

Napper, R. (2021). Not a Drama Triangle phenomenon. The Transactional Analyst, Spring, 1516.

Novey, T. (1987). An Advanced Reference Guide to the Transactional Analysis Literature. TA Associates.

Rosenberger, R. (2017). Callous Objects. University of Minnesota Press.

https://doi.org/10.5749/9781452958538

Rozenblit, L., \& Keil, F. (2002). The misunderstood limits of folk science: an illusion of explanatory depth. Cognitive Science, 26(5), 521-562. https://doi.org/10.1207/s15516709cog2605 1

Rudolph, P. (2020). Presidential Note. The Script, 129, 2-3.

Schiff, J., \& Contributors. (1975). Cathexis Reader: Transactional Analysis Treatment of Psychosis. Harper \& Row Publishers Inc.

Sedgwick, J. (2021). Contextual Transactional Analysis: The Inseparability of Self and World. Routledge.

Siddique, S. (2021). Bullying: let's tackle it head on. The Transactional Analyst, Spring, 45-46.

Sills, C. (2003). Role Lock: When the Whole Group Plays a Game. Transactional Analysis Journal, 33(4), 282-287.

https://doi.org/10.1177/036215370303300403 
Simpson, C. (2021). Bullying: reflections and resources. The Transactional Analyst, Spring, 4-6.

Steiner, C. (1971). Games Alcoholics Play. Grove Press.

Summerton, O. (1992). The Game Pentagon. Transactional Analysis Journal, 22(2), 66-75. https://doi.org/10.1177/036215379202200202

Summerton, O. (1993). Games in Organisations. Transactional Analysis Journal, 23, 87-103. https://doi.org/10.1177/036215379302300206

Summerton, O. (1993). Three-Dimensional Transactional Analysis: The Drama Triangle and the
Game Pentagon. Transactional Analysis Journal, 23(1), 30-35. https://doi.org/10.1177/036215379302300103

Timmermans, M. (2020). The Importance of an Organisational Perspective in Dealing with Workplace Bullying: "We don't take everything so seriously". Transactional Analysis Journal, 50(4), 285-297. https://doi.org/10.1080/03621537.2020.1809147

Totton, N. (2000). Psychotherapy and Politics. Sage Publications.

Williams, A. (2021). Global Connection - Global Survival. The Transactional Analyst, Spring, 41-44.

\section{Note added by the author and the editor, who are of course the same person:}

One of the reviewers raised a question about the ethics of writing about the individuals who hold, or have held, the roles referred to in this article and suggested that they be sent an advance copy.

As the author, I have now seen many publications that carry inaccurate and misleading information about what I have done in my roles as Editor and as the Chair of the World TA Conference 2020 Organising Committee (which was the only reason I was a Director of the company set up to protect the UK TA associations). I was not sent any of these in advance - I first saw the various publications when they became public.

As the editor, I appreciate that the reviewer paid attention to this aspect and realise that others may have the same thought. I have therefore agreed, in my role as the editor, with myself in the role as the author, that I will send out advance copies, labelled as not for publication, to those whose names have appeared in the various publications referred to within the article.

In both of my roles - author and editor - I hope that readers recognise that I am referring in this article to behaviours within ROLES within our TA community and not to how anyone acts as one of my professional colleagues with clients. 